\title{
Husserl y la ética de la virtud
}

\author{
Husserl and virtue ethics
}

\author{
CELIA CABRERA \\ Universidad de Buenos Aires \\ CONICET / CEF-ANCBA
}

RecIbido: 15/04/2016 Aceptado: 20/04/2016

\section{RESUMEN}

El objetivo del artículo es determinar el rol que tiene en la ética husserliana el concepto de virtud y cuál sería su relación con otras dimensiones de su ética. Con este fin, primero, presentamos los rasgos centrales de la teoría clásica de la virtud y algunas objeciones a ella formuladas. Luego, abordamos este tema en Husserl mediante el análisis de textos de la década de 1920, incluyendo textos publicados en los tomos XXXVII y XLII de la serie Husserliana. Finalmente, reflexionamos sobre el vínculo virtud - autodeterminación y sobre cómo la posición de Husserl podría resolver algunos problemas de la teoría clásica.

\section{PALABRAS CLAVE}

HUSSERL - ÉTICA - VIRTUD - NORMATIVIDAD - AUTODETERMINACIÓN.

\section{ABSTRACT}

The article aims to determine the role that has the concept of virtue in Husserl's ethics and how would its relationship with other dimensions of his ethics be. With this purpose, firstly, we sketch a presentation of the central aspects of classical virtue ethics and of the objections raised against it. Secondly, we deal with this topic in Husserl's philosophy through an analysis of texts from the 1920s, including texts published in the volumes XXXVII and XLII of the Husserliana series. Concluding, we reflect on the relationship virtue - self-determination and on the way Husserl's conception could solve some problems of the classical theory.

\section{KEYWORDS}

$$
\text { HUSSERL - ETHICS - VIRTUE- NORMATIVITY- SELF-DETERMINATION }
$$




\section{INTRODUCCIÓN}

Situar las Reflexiones de Husserl sobre ética en el contexto de las corrientes que han tenido lugar en la historia no es una tarea fácil. Husserl ha tomado elementos de posiciones tan antagónicas como las éticas racionalistas y las éticas del sentimiento, las éticas eudemonistas y las éticas del deber, siempre bajo la consideración de que en todas ellas es posible encontrar elementos que, sometidos a un análisis fenomenológico sistemático, podrían resultar fructíferos. Como sabemos, las introducciones a la ética suelen esbozar clasificaciones de las teorías que permiten comprenderlas bajo determinados rótulos. Así, es común encontrarse con la división de las éticas normativas en sistemas deontológicos, sistemas consecuencialistas y éticas de la virtud. Es en relación con este tipo de clasificaciones tradicionales que encontramos dificultades para insertar claramente su posición. Contamos, no obstante, con periodizaciones de su pensamiento que nos ayudan a situarlo en mayor o menor cercanía a estas corrientes. En este sentido, según la tradicional periodización propuesta por U. Melle, ${ }^{1}$ las reflexiones de Husserl sobre ética pueden ser divididas en dos grandes tipos de abordajes: el propio de los cursos dictados en Halle y Göttingen entre 1891 y 1914, centrado en un fuerte paralelismo entre lógica y ética, y el que comienza alrededor de 1917/18 con los cursos dictados en la Universidad de Freiburg y se consolida en la década de 1920, centrado alrededor de una teoría de la persona y una idea teleológica de la vida personal de cada sujeto. En este marco, es posible afirmar que hay en su pensamiento un pasaje desde un enfoque de tipo racionalista formal, que estaría más en cercanía con una posición deontológica de impronta kantiana, hacia una ética en la que el elemento teleológico prima sobre el deontológico. ${ }^{2}$ Vale aclarar aquí que la crítica realizada por Husserl en el segundo periodo no se dirige a la deontología en términos generales sino a un tipo de enfoque exclusivamente deontológico, es decir, exclusivamente centrado en un mandato al que el hombre debe atenerse de manera negativa. Otro tanto puede decirse de las éticas consecuencialistas, que, a diferencia de las éticas deontológicas, enfatizan el rol de las consecuencias en la fundamentación de la moralidad de las acciones. Husserl también ha dirigido críticas a corrientes que suelen enmarcarse dentro de este tipo de éticas, en especial al utilitarismo, al hedonismo e incluso a cierto tipo de eudemonismo. Ahora bien, ¿qué sucede en el caso de la las éticas de la virtud? A pesar de que en los análisis posteriores a 1920 es posible encontrar ciertos elementos que lo acercan a una posición de este tipo, Husserl critica con

$1 C f$. MELLE, U. «The development of Husserl's ethics», Études Phénoménologiques, 13-14, (1991), pp. 115-135.

$2 C f$. HART, J. «Husserl and Fichte: With special regard to Husserl's lectures on Fichte's ideal of humanity», Husserl Studies. 12, (1995), p. 152. 
gran énfasis a ciertas variantes de éticas de la virtud, en la medida en que ellas conducirían al escepticismo y al utilitarismo. ¿Cómo responder, entonces, al interrogante planteado? ¿Es posible comprender la ética de Husserl, al menos en alguna de sus vetas particulares, como una ética de la virtud?

Nuestro objetivo es intentar responder a este interrogante, esto es, determinar el posible rol que juega en su posición la noción de virtud, qué sería lo propio de su concepto y esclarecer cuál sería su relación con otras dimensiones de su ética. Con este fin, en primer lugar, presentamos un esbozo de los rasgos centrales de la teoría clásica de la virtud y de las objeciones que han sido tradicionalmente a ella formuladas. En segundo lugar, analizamos este tema en el marco específico de la ética de Husserl. Nos referimos aquí a la crítica al esteticismo ético con el fin de dilucidar lo que Husserl comprende como un «auténtico acto de virtud» (eigentliche Tugendakte). Cada vez que Husserl se refiere a la historia de la filosofía, en este caso, a la historia de la ética, se trata para él, más que de un trabajo historiográfico, de un trabajo conceptual que contribuye a delinear su propia posición. La crítica a la noción de virtud es un ejemplo del modo en que Husserl configura su propio concepto alejándose de las posiciones que, de acuerdo con él, lo han malinterpretado, dando lugar a posiciones erróneas. Por otro lado, complementamos el análisis del tema mediante el estudio de un texto titulado precisamente «Virtud» (Tugend) donde el tratamiento de esta noción es notablemente profundizado. Concluimos el trabajo abordando, por un lado, la posibilidad de hablar de una ética de la virtud en el marco de una concepción que reconoce un rol fundamental a la autodeterminación del sujeto, y por otro, el modo en que la concepción de Husserl podría constituir una alternativa que responda a algunas de las objeciones formuladas a la teoría clásica.

\section{LA ÉTICA DE LA VIRTUD}

Como sabemos, la primera formulación teórica de la ética de la virtud fue establecida por Aristóteles. Y, si bien a lo largo de la historia algunos sistemas se han inscrito en la tradición aristotélica dando un visto positivo a su concepto de virtud y otros han negado este enfoque, todas los sistemas que se reconocen como éticas de la virtud se remontan, positiva o negativamente, a la caracterización aristotélica. Por este motivo la teoría aristotélica es el mejor punto de partida para la presentación de la estructura básica de la ética clásica de la virtud.

En el Capítulo I del libro II de la Ética a Nicómaco Aristóteles distingue dos tipos de virtud (areté): la virtud moral y la virtud intelectual. Sobre la pri- 
mera afirma que ella «nace del hábito y de la costumbre» ${ }^{3}$ y sostiene que, para comprobarlo, basta advertir que no hay una sola de las virtudes morales que exista en nosotros naturalmente. Las virtudes no existen por la sola acción de la naturaleza, sino que la naturaleza nos ha hecho susceptibles de ellas y es el hábito el que las desenvuelve y perfecciona en nosotros. Es posible encontrar un patente ejemplo de esto, según él, atendiendo a lo que sucede con nuestros sentidos, ya que:

No es a fuerza de ver ni a fuerza de oír como adquirimos los sentidos de la vista y del oído sino que, por el contrario, nos hemos servido de ellos porque los teníamos; y no los tenemos en modo alguno porque nos hemos servido de ellos. Lejos de esto, no adquirimos las virtudes sino después de haberlas previamente practicado. ${ }^{4}$

La virtud, entonces, no es ni una pasión, ni una facultad, sino un hábito o cualidad adquirida. Mientras que como «pasión» o «afección» Aristóteles comprende el deseo, la cólera, el temor, la alegría y, como «facultad» a las potencias que hacen que seamos capaces de experimentar las pasiones, un hábito es la disposición moral buena o mala en que nos encontramos para sentirlas. Así, «por ejemplo, en la pasión de la cólera», dice el filósofo, «si la sentimos demasiado viva o demasiado muerta es una disposición mala y si la sentimos en una debida proporción, es una disposición que se tiene por buena». ${ }^{5}$ Por este motivo, Aristóteles se refiere a la virtud como una clase de héxis, ${ }^{6}$ esto es, como un modo de ser del individuo que refiere a una disposición del carácter respecto de las pasiones. Esta definición de la naturaleza y origen de la virtud, según la cual ella refiere a una tendencia o disposición a actuar correctamente, es un aspecto central que, hasta donde llega mi conocimiento, ha persistido aún en las más variadas versiones de esta teoría. Siguiendo con la caracterización de la virtud como un hábito debemos decir que no es un hábito cualquiera, para ser más precisos, a diferencia de otro tipo de hábito, no es simplemente una disposición a actuar correctamente sino una disposición a actuar correctamente por una razón. En este sentido, Aristóteles señala que la virtud es un hábito que depende de nuestra voluntad, y que está regulado por la razón en la forma en que lo regularía el hombre verdaderamente sabio. ${ }^{7}$ Para que se pueda hablar de virtud, según esto, es preciso satisfacer las siguientes condiciones:

3 ARISTOTELES, Ética Nicomaquea. Tr. Patricio de Azcárate. Buenos Aires, Losada, 2004, p. 49.

4 Ibid, p. 50.

5 Ibid.

$6 C f$. ARISTÓTELES, Etica Eudemia, tr. Carlos Megino Rodriguez, Madrid, Alianza, 2002, p. 12 ss.

7 ARISTÓTELES, Etica Nicomaquea, p. 65. 
Es preciso que el que obra se halle en cierta disposición moral en el momento mismo de obrar. La primera condición es que sepa lo que hace; la segunda que lo quiera así mediante una elección reflexiva y que quiera los actos que produce a causa de los actos mismos; y, en fin, es la tercera que al obrar, lo haga con resolución firme e inquebrantable de no obrar jamás de otra manera. ${ }^{8}$

El rol otorgado a la razón práctica en la constitución de la virtud es un aspecto que ha sido objeto de disputa en la discusión ética. La teoría clásica otorga un rol a la racionalidad práctica que en las distintas vertientes de esta teoría ha sido reforzado o debilitado. En efecto, al afirmar que la virtud consiste en tomar en todas las cosas el justo medio, evitando el exceso y el defecto, Aristóteles aclara que este justo medio es el deber que prescribe la recta razón. En lo que concierne al desarrollo del entendimiento ético que conduce al sujeto a adquirir la disposición a la virtud, él ha sido tradicionalmente considerado como la adquisición de una habilidad práctica y, de este modo, como algo que puede ser aprendido. A propósito de este aspecto también encontramos el antecedente más importante en Aristóteles quien ha afirmado que, así como para convertirse en un arquitecto es preciso aprender a construir y que esto solo es posible construyendo, para ser una persona justa, es preciso aprender y esto solo se logra realizando acciones justas. ${ }^{9}$ Ahora bien, sabemos que todo aprendizaje práctico y toda acción tienen lugar en el marco de una tradición que prescribe lo que debe considerado bueno. A la luz de esto, es preciso agregar que la virtud no supone solo la adquisición de un saber práctico sino también una comprensión reflexiva de lo heredado; requiere ir más allá de lo adquirido pasivamente mediante la transmisión social para evaluar cómo actuar en una situación particular.

En la base de la definición aristotélica se encuentra otro elemento que también ha perdurado en el tiempo, distinguiendo a la ética de la virtud de otros abordajes en ética. Nos referimos con esto a que al hablar de virtud se alude a algo que hace de un sujeto un sujeto bueno. En otras palabras, para la ética de la virtud es relevante qué tipo de persona es el sujeto, lo que interesa es su vida considerada como una unidad global, la educación moral y el desarrollo personal y no meramente la calificación de acciones consideradas como hechos particulares, yuxtapuestos e independientes. No se trata tampoco de comprender la disposición a la virtud considerada en términos de la frecuencia de acciones virtuosas, sino de la definición de las acciones en referencia a las razones del sujeto para actuar. Cuando, por ejemplo, una persona honesta decide actuar honestamente, no se trata de una acción casual sino de una decisión, una elección

8 Ibid.

9 Cf. Ibid, 49. 
basada en su disposición a ser una persona honesta. Esta es la idea que expresa la afirmación final del pasaje arriba citado en el que Aristóteles afirma como condición de la virtud que el sujeto, al obrar, lo haga con resolución firme e inquebrantable de no obrar jamás de otra manera. En otras palabras, el concepto de virtud está estrechamente unido a la idea de «persona ética», e implica una concepción de la vida como un todo unitario y no como una sucesión de estados más o menos desconectados entre sí. Estrechamente unido a esto se encuentra el último rasgo de la ética de la virtud al que haremos referencia: la idea de que ella contribuye a la consecución de una finalidad hacia la que se orienta la totalidad de la vida. El fin al que la virtud contribuye es lo que ha sido denominado ya en la tradición griega antigua «felicidad» (eudaimonia). Ha sido Aristóteles, nuevamente, quien ha sentado las bases de esta consideración de la felicidad como el fin de todos los actos del hombre pues «puede decirse realmente de todas las cosas del mundo que solo se las desea en vistas de otra cosa excepto la felicidad, porque ella es en sí misma fin».. ${ }^{10}$ Un tema fundamental de la concepción de la felicidad unida a la virtud es su separación respecto de toda connotación hedonista y utilitarista del concepto y, por otro lado, que no se trata de una definición de la felicidad que sea independiente de la virtud misma: la vida conforme a la virtud es ya la vida feliz.

En suma, la ética de la virtud se asienta en la noción de hábito y de habilidad práctica; el ejercicio de la razón práctica; en una concepción unitaria de la vida que otorga un rol central a la persona y en la idea de un fin último al que se dirigen las acciones virtuosas. Esta presentación esquemática facilita la comprensión de los motivos por los cuales diferentes corrientes éticas han objetado esta posición, ya que tradicionalmente lo han hecho dirigiendo sus críticas a alguno de los puntos señalados. Así, por ejemplo, la deontología la ha acusado de ser una teoría acerca de qué tipo de persona debe ser un sujeto y no acerca de qué debe hacer. Si una virtud es una disposición a hacer lo correcto, esto supondría dilucidar qué es lo correcto y por qué lo es. Ahora bien, ¿puede la ética de la virtud otorgarnos una teoría de la acción correcta? Su déficit sería que ella no podría proveer una guía para la acción en la forma de un conjunto de reglas que puedan ser comprendidas por todos y no solo por las personas virtuosas. En otras palabras, la ética de la virtud sería una teoría adecuada para dar cuenta del fenómeno de la motivación moral, pero no de la obligación moral. Por otro lado, la virtud tiene un aspecto afectivo, ligado a lo adquirido de manera pasiva y un aspecto activo, ligado al enjuiciamiento racional. Ambos aspectos dan lugar a importantes ejes de discusión que deben ser dilucidados: una posición que acentúe el aspecto afectivo en desmedro del 
rol de la racionalidad podría sostener que la persona virtuosa es aquella que actúa de manera correcta por la razón correcta, sin un conflicto u oposición interna a la que tenga que combatir, que la oriente en sentido contrario. Aquí cabría preguntarse en qué medida podemos llamar a esto virtud pues, ¿cuál sería el valor ético de seguir un impulso ciego que casualmente resulte dar lugar a acciones buenas y virtuosas? Si, por el contrario, enfatizamos el aspecto activo es preciso esclarecer cuál es el rol del razonamiento práctico y responder a este interrogante evitando el riesgo de caer en una posición excesivamente intelectualista. Por último, resta mencionar un problema crucial de la teoría presentada. Hemos señalado repetidas veces que la virtud es una disposición. Sin embargo es a todas luces evidente que hay disposiciones que no son virtudes, ... sino meros rasgos de carácter, ¿cómo determinar entonces lo propio de la virtud frente a otros tipos de disposición?

Sin entrar en más detalles acerca de las innumerables críticas y vertientes históricas de esta teoría, damos por finalizada aquí la presentación general para adentrarnos en la posición de Husserl. Con este fin, nos referimos a continuación a un fragmento del curso Introducción a la ética dictado en 1920/24. Retomaremos lo desarrollado aquí cuando, concluyendo el trabajo, abordemos el modo en que la ética husserliana podría ofrecer una respuesta a algunos problemas de la teoría clásica.

\section{LA NOCIÓN DE VIRTUD EN LA ÉTICA DE HUSSERL}

\section{III.1. VIRTUD Y REFLEXIÓN EN EL MARCO DE LA CRÍTICA AL ESTETICISMO ÉTICO: ACTOS FUNDANTES DE LA MORALIDAD Y ACTOS VIRTUOSOS.}

Gran parte del curso Introducción a la ética toma como hilo conductor un estudio histórico-crítico que provee a Husserl el material que despeja el camino hacia las propias intelecciones sistemáticas. En el capitulo VII de estás lecciones, ${ }^{11}$ Husserl aborda dos posiciones que surgieron en respuesta al naturalismo y sensualismo de Hobbes: la matematización de la ética y el esteticismo ético. Luego de demostrar el carácter problemático del paralelismo entre ética y lógica defendido por Cudworth y Clarke, Husserl se refiere a la respuesta a Hobbes que proviene de los defensores del llamado «sentido moral». Comienza allí por un profundo análisis de la posición de Lord Schaftesbury, a quien presenta como quien elaboró una de las primeras teorías morales basadas en el sentimiento, que se ha ganado el lugar de un clásico al que se retrotrae toda una tradición de filosofía moral. Contra su principal enemiga, la «escuela

11 HUSSERL, Edmund. Einleitung in die Ethik, Vorlesungen Sommersemester 19201924, (Husserliana XXXVII). Dordrecht/Boston/London: Kluwer Academic Publishers, 2004, pp. 125-171. 
del egoísmo ético» representada por Hobbes, Schaftesbury sostiene la existencia de un sentido moral cuya fuente es la naturaleza humana y cuyo fin es la felicidad. La compasión y la bondad serían ejemplos de estos sentimientos morales naturales que facilitan la virtud en el hombre. Según Schaftesbury, sobre estos sentimientos primeros se montan otros de segundo orden, ya no de carácter natural sino en los que participa la razón. Sin embargo, un punto central de su teoría es que ninguna segunda naturaleza puede borrar el sentido natural virtuoso. Esto se debe a que entre los afectos naturales que garantizan la tendencia natural del hombre hacia el bien y los afectos sociales existe, según este autor, una armonía que configura un sentido moral facilitando, así, la virtud en el hombre.

Arrastrado por un ferviente esteticismo y, según Husserl, por la falta de cientificidad y claridad en sus ideas, Schaftesbury consideró que el sentimiento de aprecio moral es un caso particular de sentimiento estético. Aunque esta consideración, que hace de la moral una estética del sentimiento y conduce a la identificación de ética y estética, es objeto de importantes críticas, ${ }^{12}$ hay en lo que concierne a la noción de virtud de Schaftesbury, un aspecto que Husserl considera interesante: este autor, a diferencia de otros defensores de la moral del sentimiento, ha reconocido que, para que se trate realmente de virtud, el hombre debe ser capaz de reflexionar, i.e., ha reconocido la necesidad del ser humano de reflexionar sobre sus afectos para ser virtuoso. Husserl continúa con su análisis y detecta en él, no obstante, una nueva fuente de problemas. El problema de esta concepción radicaría en que, aunque el análisis de las acciones al que se refiere Shaftesbury al hablar de reflexión, sea una actividad intelectiva, el que califica dichas acciones, según el autor inglés, es el sentido moral y no el sujeto a través de un enjuiciamiento reflexivo de sí mismo. Frente a esto Husserl pregunta:

¿Podemos decir sin más que la justificación mediante una valoración retrospectiva que corresponde a los actos del sentimiento y la voluntad de nivel inferior alcanzan para que el sujeto sea juzgado como moral? ¿Reside realmente la moralidad en estos actos inferiores, sea, como dice Schaftesbury, en una cierta armonía que ellos muestran ${ }^{13}$

Como podemos suponer, su respuesta es negativa, ya que:

El alma no es un piano, frente al que el yo se sienta a ensayar como un pianista ya diestro y habilidoso [...] el yo moral, el yo de la perpetua e incesantemente

12 Cf. Ibid, p. 166-167

13 Ibid, p. 161. Traducción propia. (En adelante, en todos los casos en los que se citen obras en lengua extranjera no se especifique traducción, ésta es propia) 
educación de sí mismo, es el yo que quiere mejorarse a sí mismo, que quiere volver a crearse de tal modo (a sí mismo como yo) de modo que como yo ético eo ipso solo puede querer el bien. Allí yace un enjuiciamiento reflexivo que es una autovaloración. Ciertamente pueden enjuiciarse los actos y afectos simples pero el punto más alto (Spitze) de la aprobación o desaprobación se halla dirigido hacia el yo. ${ }^{14}$

En resumen, aunque su mérito fue el reconocimiento de la aprobación reflexiva de los actos de virtud, inmediatamente confundió el mero enjuiciamiento de los afectos del nivel más ingenuo con aquel enjuiciamiento de sí mismo (Selbstbeurteilung) que exige la moralidad en sentido propio, del mismo modo en que mezcló la regulación de las acciones según reglas morales establecidas autónomamente por el sujeto mismo, con la regulación de las acciones según la belleza. Por otro lado, al hacer depender la moral de un sentido pasivo, que asimila a un gusto estético, Schaftesbury se limita a elaborar una estética de los afectos que comete el error de dejar de lado el gran problema de la razón.

A pesar de que Husserl critica desde sus bases la posición de Schaftesbury considera que en su obra hay intelecciones importantes. Sobre la base de estás intelecciones y mediante su apropiación crítica, Husserl comienza el desarrollo de lo que constituye su propia posición sobre la virtud. El verdadero concepto de virtud no designa una mera determinación pasiva incorporada, sino un plus de actividad del sujeto, que lo modifica y renueva en su actuar. La virtud es considerada por Husserl, al modo de Aristóteles, como un hábito. Se trata de una habitualidad que «tiene aquí» dice Husserl «como por lo demás respecto del yo y su vida moral, un carácter fenomenológico acuñador, un sello moral, cuya intencionalidad siempre puede ser desplegada por repetición de los actos correspondientes, los cuales conforman la moralidad». ${ }^{15} \mathrm{El}$ yo moral juzga su comportamiento y sólo en la medida en que juzga reflexivamente se determina a sí mismo. Así, «El maravilloso fenómeno de la determinación de sí mismo» ${ }^{16}$ configura una segunda naturaleza que permanece en el sujeto y obra motivándolo de manera habitual.

Ahora bien, a fin de comprender qué entiende Husserl por virtud y esclarecer la relación existente entre virtud y reflexión es preciso atender a una distinción entre dos tipos de actos morales, que es presentada finalizando la exposición sobre Schaftesbury. Esta distinción es muy valiosa para nuestro tema pues según ella debemos separar (1) los actos originariamente fundantes de la moralidad (die Moralität ursprünglich stiftenden Akte), los creativamente constituyentes, de (2) los actos auténticamente virtuosos (die eigentlichen

14 Ibid, p. 162.

15 Ibid, p. 163.

16 Ibid, p. 162. 
Tugendakte), que son aquellos que tienen lugar según el acuñamiento habitual de la moralidad en un yo que se sabe como moral de un modo habitual. Esta separación entre «actos fundantes de la moralidad» y «actos virtuosos» significa fundamentalmente que hay actos reflexivos que crean el yo ético de modo original y actos, fundados en ellos, que son ejecutados sin reflexión en el sentido especifico de que son realizados por personas que ya desarrollaron un carácter ético. Estos últimos actos son, en sentido estricto, los actos virtuosos. De este modo, Husserl coincide con la concepción clásica descripta en el primer apartado en que la virtud es un tipo especial de habitualidad. Pero enriquece la concepción de este concepto (que de otro modo podría confundirse con una tendencia pasiva) al considerarlo en términos de un saberse a sí mismo como yo moral de modo habitual, que es primariamente instituido por un acto creativo, fundante de la moralidad, mediante una crítica reflexiva que deja una marca en él. La noción de virtud en la ética de Husserl está íntimamente ligada al ejercicio de la razón práctica y en nada se asemeja a la asunción pasiva de lo heredado o al seguir una tendencia ciega que oriente al sujeto casualmente a realizar acciones buenas. La persona ética no es el alma bella (schöne Seele) que goza de la inocencia del paraíso, sino que está fundada en su propia actividad crítica y reflexiva. Adelantando palabras del texto que analizaremos a continuación podemos decir que, otorgarle un lugar a la virtud en la ética de Husserl no debe hacernos perder de vista que para él «todo actuar es actividad, todo ser bueno (Gutsein) es un valor constituido en la actividad. Un bien práctico solo es lo que se constituye en una actividad de elección entre valores». ${ }^{17}$ Pero, ¿es suficiente la reflexión y el actuar según la razón para poder afirmar que se trata de una acción virtuosa? ¿Sobre qué fundamento se basan la reflexión y el ejercicio de la racionalidad en la elección ética? En lo sucesivo intentamos responder a este interrogante abordando a un aspecto fundamental de la vida moral, según Husserl, al que aún no nos hemos referido.

\section{III.2. VIRTUD Y MOTIVACIÓN}

En el texto de 1920 titulado «Virtud» (Tugend) Husserl se pregunta con mayor profundidad cuál es el carácter propio de la acción moral a partir de su vínculo con la dimensión valorativa y la normatividad de la valoración. Su respuesta pone énfasis esta vez en un factor que hasta este momento no hemos considerado: la motivación que subyace a la acción auténticamente moral.

Cuando hablo de virtud, tengo en mente la lucha entre un aspirar práctico (una tendencia de la voluntad) que se dirige a lo tenido por bueno (Für-gut-Gehaltenes)

17 HUSSERL, E. Grenzprobleme der Phänomenologie, Texte aus dem Nachlaß 1908-1937 (Husserliana XLII) Dordrecht/Heidelberg/New York/London: Springer, 2013, p. 279 
y una mera inclinación, es decir, una tendencia a querer algo deseado, eventualmente con pasión, que no es algo reconocido o tenido por bueno. ${ }^{18}$

Este texto completa lo dicho hasta aquí mediante la consideración de la acción moral como una dirección de la voluntad hacia algo reconocido como positivamente valioso. Al caracterizar la virtud de este modo, Husserl reconoce la necesidad de esclarecer más de cerca la diferencia pues ¿no es todo anhelar un «tener-por-valioso»? ¿y no es todo sentir (Fühlen) un mentar a algo como bueno? Este interrogante lo conduce a la distinción entre el «tener-algo por-valioso» en sentido general y en sentido especifico: si bien es verdad que todo amar es un «tener-por-amado», que todo agrado es un «tener-por-agradable», es decir, es agrado por algo que aparece (erscheint) como agradable, en todos estos casos podemos también plantear la pregunta por la racionalidad de la valoración y preguntarnos, por ejemplo, si lo mentado como agradable es realmente digno de ser considerado agradable o si lo amado es digno de serlo. En este sentido específico del «tener-por-valioso», lo que entra en consideración es la cuestión de la comprobación o justificación del valor concedido a algo. En este contexto, Husserl se refiere a una normatividad interna de la voluntad en virtud de la cual ella se dirige al mentado valor bueno y halla en él su plena conformidad, en la medida en que este valor prueba ser un valor verdadero. Aquí, agrega, se abre la posibilidad de que un valor considerado bueno resulte no serlo porque impide la realización de un valor superior. Según ley de esencias, la voluntad se ve privada de su verdadera satisfacción y normatividad, cuando descubre que hubiera podido hacer algo mejor. ${ }^{19}$

Husserl continúa considerando el caso de la acción que, a pesar de ser un aspirar por mera inclinación, puede eventualmente tener su bien inmanente en la medida en que se adecúa al estilo tradicional. Sin embargo, insiste en su distinción respecto del actuar a partir de fuentes intuitivas justificadas ya que es solo esto último lo que permite el nacimiento de un hábito o tendencia práctica habitual. Actuar moralmente implica, para él, decidirse por un valor y comprometerse con él. Aquí hace su aparición la idea de un yo moral que se determina a sí mismo y configura sus acciones en vistas a un ideal de sí mismo.

18 Ibid, p. 279.

19 Para comprender esto debemos tener en cuenta que, tomando como eje la llamada «ley de absorción» (que indica que solo aquella opción que absorbe el valor de toda otra, sin ser ella misma absorbida, posee valor práctico absoluto), en sus lecciones tempranas Husserl enuncia la ley superior de la práctica formal, el imperativo categórico, del siguiente modo: «iHaz lo mejor entre lo alcanzable en toda tu esfera de influencia práctica!» (Tue das Beste unter dem erreichbaren Guten innerhalb deiner jeweiligen praktischen Gesamtsphäre!). HUSSERL, E. Vorlesungen über Ethik und Wertlehre 1908-1914 (Husserliana XXVIII), Dordrecht/Boston/ London: Kluwer Academic Publishers,1988, p. 142. 
El rol de la motivación en la caracterización de la auténtica vida moral es tan fundamental que incluso las acciones ejercidas mediante reflexión no alcanzan el status de acciones plenamente morales si falta en ellas el compromiso con un valor ético de un modo que atraviese la totalidad de la vida. El análisis de la acción ingenuamente buena es abordado mediante la consideración del caso que en la tradición estética ha sido denominado «el alma bella» (die schöne Seele). Se trata de aquellas personas que harían el bien instintivamente, sin la necesidad de reflexionar antes de actuar. En sus palabras, de aquellos «que no necesitan la crítica moral y el apoyo de las máximas y leyes morales». ${ }^{20}$ En este marco, se refiere a la existencia de instintos irracionales que amenazan con absorber toda la atención (Aufmerksamkeit), toda acción yoica (Ich-Aktion) y arrastrar consigo los valores correspondientes. Allí Husserl repite algo que ya nos resulta conocido, a saber, que lo propio del alma armoniosa es la moderación de tales instintos irracionales por medio de la educación (Erziehung) y la auto-coacción (Selbstzwang). Esta moderación es, naturalmente, realizada mediante un acto reflexivo. Ahora bien, resulta interesante la distinción allí introducida entre la mera reflexión o sopesamiento racional en la elección, por un lado, y la autentica elección moral, por el otro. Pues,

Esta reflexión y toda racionalidad en la elección pueden efectuarse concreta e intuitivamente de manera aislada sin que haya sido perseguida y efectuada una regulación universal de la totalidad de la vida y una regulación del yo por el yo mismo, en definitiva, una regulación bajo el punto de vista del valor, de la dignidad, de la santidad del sujeto de la voluntad, en tanto yo que es bueno en el sentido más alto, o bajo el punto de vista de la auto-normatividad, a través de su innato ideal de yo (durch sein eingeborenes Ichideal), el yo que yo debo (soll) ser. ${ }^{21}$

La distinción, como vemos, atañe a las elecciones efectuadas en vistas a una configuración total de la vida según una norma y a las elecciones reflexivas efectuadas de manera aislada. El valor otorgado a la motivación de la acción, tanto en lo que concierne al reconocimiento de su valor, como al compromiso con él de un modo que atraviese toda la vida del sujeto nos muestran una vez más un rasgo que Husserl comparte con la ética clásica de la virtud: la idea de un yo moral que «no realiza acciones buenas concretas de modo yuxtapuesto y que retrocede ante lo malo, que no es el yo que se pone como meta lo bueno de modo intuitivo», ${ }^{22}$ sino que se educa a sí mismo consecuentemente hacia su yo norma, hacia su determinación, se busca a sí mismo (sich selbst suchende Ich) y que rige a partir de esto toda su vida práctica. A diferencia de un actuar

20 HUSSERL, E. Grenzprobleme der Phänomenologie, p. 283.

21 Ibid.

22 Ibid.

Contrastes vol. XXII-N² (2017) 
enjuiciador normativo, la acción del alma bella aparece aquí caracterizada como un actuar «conforme al deber» (pflichtmäßig), de carácter ingenuo. Husserl sitúa el actuar bueno pero ingenuo un escalón más abajo de la moralidad auténtica, descripta como una elección de valores en plena actividad. ${ }^{23}$

Así, es preciso distinguir entre (1) la acción por inclinación que se dirige a algo no reconocido como bueno, (2) la acción «conforme al deber» que se dirige a lo bueno pero ingenuamente y (3) la acción según normas que de modo evidente, metódico y científico persigue lo bueno porque lo reconoce como lo mejor posible a realizar. El tema adquiere aún mayor complejidad cuando inmediatamente Husserl mismo se pregunta si existe realmente algo más que el actuar «conforme al deber» que deba ser tenido en consideración al hablar de una humanidad plenamente ética, y postula como una tarea de la ética «sopesar si es posible (y debida) una completa moralización del actuar, de todas y cada una de las acciones». ${ }^{24} \mathrm{El}$ carácter del texto que estudiamos da cuenta de las dificultades para ofrecer una respuesta definitiva a este interrogante, se trata de un manuscrito en el que Husserl plantea preguntas que no termina de responder completamente ya que va siguiendo el ritmo de sus reflexiones. Volveremos sobre este tema en las conclusiones. Por el momento esperamos haber dejado al menos planteada la complejidad de la concepción husserliana de la virtud en lo que concierne a la motivación y el actuar según normas.

\section{III.3. VIRTUD Y FELICIDAD}

En lo relativo a la autorregulación universal de la vida la ética, Husserl considera asimismo otro tópico de la ética de la virtud: la felicidad como fin último al que aspira la vida virtuosa. En sentido estricto, la felicidad (Glückseligkeit) ${ }^{25}$ es la culminación de una serie de niveles en los que se despliega la vida ética y que tienen su punto de partida en la «conciencia ética», que permite al hombre contemplar su vida como una totalidad y pre-configurarla en función de una meta. La autoconciencia es, para Husserl, la capacidad del hombre de reflexionar sobre su conducta y enjuiciarse a sí mismo, de valorar sus actos, sus motivos,

23 Cf. Ibid, p. 280.

24 Ibid.

25 El sentido del concepto «Glückseligkeit» que Husserl toma aquí es muy cercano a la idea de Fichte de una «vida bienaventurada» o «vida bendita» (selig), aunque no idéntico a él ( $C f$. FICHTE, J.G. Die Anweisung zum seligen Leben, oder auch die Religionslehre, Hamburg: Meiner, 1954). El término «selig» contenido en «Glückseligkeit» contiene una connotación religiosa, que el español «felicidad» no recoge de modo inmediato, y que lo distingue del término alemán «Glücklichkeit». Sin embargo, tampoco puede traducida como «dicha», «bienaventuranza»o «beatitud», para lo cual existe el término alemán «Seligkeit». De este modo, si bien lo traducimos como «felicidad» debemos tener en cuenta que, en sentido estricto, no hay un equivalente en español para él. 
los medios y los fines en el dominio de sus posibilidades prácticas. Esta actitud crítica respecto de las tomas de posición anónimas de la vida cotidiana y de constante auto-percatación de las tendencias que nos guían corresponde a lo que en el segundo volumen de Filosofía Primera Husserl denomina «epojé ética universal». ${ }^{26}$ Una epojé ética que asume una función paralela a la epojé trascendental en su tarea de «desvelar» en encubrimiento inicial del origen constitutivo: en un sentido análogo a lo que sucede en el ámbito teórico, la conversión a la que se refiere Husserl al hablar de la efectuación de una «epojé ética» no tiene tanto que ver con un abandono de las metas y los valores de los que se trate como con la búsqueda de su justificación y evidencia.

En un segundo nivel, Husserl se refiere a la habitualidad de comportarse según la conciencia ética, con la expresión «ethische Gesinnung». En este nivel, las decisiones tienen el carácter de una inclinación a decidirse de un modo particular. Esta autorregulación de la vida ética presenta, a su vez, dos niveles: el nivel inferior de regulación implica una toma de distancia respecto de mi vida cotidiana y sus metas parciales y la proyección de una meta que abarque mi vida entera. Husserl ejemplifica este nivel pre-ético en el que decidimos regular nuestra propia vida en función de una meta al referirse a la elección de una profesión (Beruf). Sin embargo, la autorregulación que entra en juego en la elección de una profesión es limitada, esto es, hay aspectos de nuestra vida que permanecen fuera de su gobierno. De allí que en el nivel más alto de auto-regulación, que constituye el nivel estrictamente ético, Husserl piense más bien en una autorregulación universal de la vida en la que las formas preéticas de regulación son sometidas a una crítica en vistas a normas absolutas. Es en este punto donde se introduce la temática de la felicidad. Primeramente Husserl considera que la traducción permanente del punto de vista ético en acciones justificadas da lugar a la condición de «estar en paz consigo mismo» o «conformidad consigo mismo» (Selbstzufriedenheit). Esta conformidad no está relacionada con el placer y excluye el permanecer pasivo en la satisfacción, por eso es descripta como una «alegría reflexiva» (reflektive Freudigkeit). ${ }^{27}$ Sin embargo, aclara inmediatamente que el hombre solamente conforme no es aún un hombre feliz. La conformidad con la acción propia es condición de posibilidad de la felicidad, pero esta última supone algo más a saber, «la conformidad con mis dotes naturales (Naturgaben), con mi salud, conformidad con el mundo circundante y con el mundo como mi campo de acción». ${ }^{28} \mathrm{La}$ felicidad supone, entonces, la conformidad del sujeto con el resultado de las

26 HUSSERL, E: Erste Philosophie (1923/24). Zweiter Teil. Theorie der phänomenologischen Reduktion. (Husserliana VIII), Den Haag, M. Nijhoff, 1959, p. 319.

27 HUSSERL, Grenzprobleme der Phänomenologie, p. 331.

28 Ibid, p. 311 
acciones orientadas al futuro y, asimismo, con lo pre-dado como condición de su acción. En este punto Husserl afirma que ella entra en tensión con la virtud en la medida en que, a pesar de sus esfuerzos, el hombre está sujeto al advenir de la irracionalidad del azar (Zufall) y del destino (Schicksal). No obstante, el hecho de que nuestra experiencia sufra decepciones, lejos de tener un carácter negativo, es el punto de partida de una motivación para la crítica que apunta a la reorganización de nuestra propia vida.

Por último, vale agregar que la virtud y la felicidad a la que ella aspira no son, para Husserl, ideales individuales. La vida virtuosa es la vida que aspira al mejoramiento de la humanidad, al acrecentamiento de su valor y de su racionalidad en un proceso que, aunque quizás nunca sea completamente plenificado, y quizás precisamente por eso, no deja de motivar al hombre hacia su realización plena.

\section{CONCLUSIÓN}

Según lo expuesto, una característica central de la comprensión de Husserl de la vida ética es que ella no puede ser alcanzada mediante una habitualidad totalmente pasiva. La adopción pasiva de una conducta virtuosa aceptada tradicionalmente, incluso si configura su carácter de un modo positivo, no hace de un sujeto una persona moralmente buena. Reforzando esta idea Husserl ha sostenido que la cultura objetiva en la que el hombre habita solo tiene valor como sustrato para la posibilidad de configurar valores superiores. ${ }^{29} \mathrm{~A}$ pesar de que nuestro autor acuerda con Schaftesbury en que los actos virtuosos se convierten en una «segunda naturaleza», es fundamental para él que la vida ética tenga su origen en la actividad del ego y no en un proceso de habitualidad totalmente ingenuo y a-reflexivo. En este marco, resulta evidente que el eje central del que depende la respuesta a la pregunta por la relación entre la ética husserliana y la ética de la virtud, gira en torno a la posibilidad de combinar esta noción con una ética que, tal como hemos visto, concede un rol fundamental a la autodeterminación del sujeto. Expresado con mayor claridad, si consideramos que la vida ética tiene su origen en la actividad libre y espontánea del ego e interpretamos la virtud como una mera disposición, debemos concluir que la ética de Husserl no podría de ningún modo ser entendida en términos de una ética de este tipo. El énfasis en los actos voluntarios de autodeterminación debería entenderse, más bien, en proximidad a una ética de tipo kantiano. ¿Es preciso, entonces, desechar tal idea en favor de una interpretación de la ética de Husserl al modo de una ética moderna? O bien, como señalamos, comprendemos las virtudes como actos ejecutados sin reflexión, efectuados como una disposición pasiva que se opone a la idea de autodeterminación y desechamos, 
así, este concepto, o bien consideramos que lo que sucede en realidad es que Husserl combina la ética aristotélica con teorías modernas de la subjetividad que ponen especial énfasis en los actos voluntarios del sujeto. En este sentido, podemos pensar, como plantea Henning Peucker, que su teoría a partir de los años 20 reinterpreta la noción de virtud «por un lado, esclareciendo el origen de las virtudes en la actividad libre del sujeto y, por otro, extendiendo la concepción voluntarista de la subjetividad hasta abarcar los hábitos constituidos pasivamente»». ${ }^{30}$ Considero que esta última posición, no sólo es más cercana a Husserl sino que también contribuye a hacer más interesante la reflexión al superar los antagonismos que han atravesado la historia de la ética.

Siguiendo esta línea quisiera, por último, retomar la presentación del primer apartado para esbozar brevemente el modo en que el tratamiento de la virtud realizado por Husserl -en estrecha conexión con otros rasgos de su teoría que aquí no hemos desarrollado- podría responder a algunos interrogantes a los que la teoría clásica de la virtud da lugar. En lo que concierne a la crítica acerca de la imposibilidad de la teoría clásica de ofrecer un criterio moral que nos guíe en nuestras elecciones, podemos decir que la ética husserliana articula el ideal ético de una vida virtuosa sin renunciar al elemento deontológico. Aunque es cierto que a partir de 1920 el imperativo categórico no tiene el mismo rol que tuvo en los cursos tempranos, no es tan claro que se trate de un abandono del mismo y no más bien de una reinterpretación a la luz de los nuevos resultados obtenidos. De cualquier modo, es innegable que Husserl continua sosteniendo la exigencia de actuar según normas, aunque la concepción misma de la normatividad ética sea luego reinterpretada por él en función de los determinantes personales, hasta el punto de otorgar una legitimidad ética superior a las vocaciones que tienen su fuente en el amor. Por otro lado, hemos mencionado el doble riesgo que corre la ética de la virtud al señalar que un excesivo énfasis en el aspecto racional de la elección traería consigo el peligro de caer en una posición extremadamente intelectualista, mientras que el acento del aspecto afectivo amenazaría con convertir la virtud en una pasividad ciega que no tendría nada cercano a la moralidad. Sobre el primer peligro podemos decir que, a pesar de que Husserl se ha esforzado por elaborar una ciencia ética alejada del relativismo, se ha esforzado igualmente en evitar confinar todos los aspectos de la vida práctica a la dimensión teórica. En lo que respecta al segundo peligro mencionado, todo lo desarrollado hasta aquí da cuenta de que tal posibilidad es, a todas luces, inviable en el pensamiento ético de Husserl. En suma, la relación de Husserl con la ética de la virtud puede ser examinada desde muchos puntos

30 PEUCKER, Henning. «From Logic to the person: an introduction to Edmund Husserl's Ethics», The Review of Methaphysics, 62, (2008), p. 325. 
de vista que aquí no hemos agotado. Desde una perspectiva general, situar la ética husserliana en el contexto de la historia de la ética permite comprender la riqueza de sus propios conceptos y mostrar, a su vez, que ella no puede ser subsumida bajo ninguna categoría estática.

Celia Cabrera es Doctora en Filosofía por la Universidad de Buenos Aires y becaria del CONICET

Líneas de Investigación:

Fenomenología, Ética fenomenológica.

Publicaciones recientes:

- «La apropiación husserliana del imperativo categórico», Areté. Revista de Filosofía. Vol. 29, N 1, 2017, pp. 29-58. Pontificia Universidad Católica del Perú. ISSN: 1016-913X

-«Amor y moralidad en la ética tardía de Husserl», Ideas. Revista de Filosofía Moderna y Contemporánea, Vol. 1, № 2, 2015, pp. 44-70. RAJGIF Ediciones, Buenos Aires. ISSN 2451-6910

- «Sobre la racionalidad de la esfera afectiva y su vínculo con la razón teórica en la ética de E. Husserl», Revista de Filosofía, Vol. 39, ํ 1, 2014, pp. 73-94, Universidad Complutense de Madrid, ISSN 0034-8244

Correo electrónico: celiacabrera@gmx.com 
